\title{
Rethinking Learning in a Digital Age: Outcomes from EDUsummIT 2017
}

\author{
Joke Voogt ${ }^{1,2}$ (D) Gerald Knezek ${ }^{3}$ \\ Published online: 3 August 2018 \\ (c) The Author(s) 2018
}

\begin{abstract}
"Rethinking learning in the digital age" was the theme of EDUsummIT 2017, which was held in Borovets, Bulgaria in September, 2017. Approximately 100 policy makers, practitioners and researchers met to discuss key topics in nine Thematic Working Groups. These topics were: (1) education systems in the digital age: the need for alignment; (2) informal learning with technology; (3) professional development for technology-enhanced learning leaders; (4) digital agency to empower equity in the classroom; (5) formative assessment supported by technology; (6) developing creativity in teachers and learners; (7) learning from national policy experiences;(8) upbringing in a digital world: opportunities and possibilities of schooling, and (9) sustainability and scalability of technology integration initiatives. In this special issue we present the scholarly articles that were written after EDUsummIT 2017, based on discussions within the Thematic Working Groups during the meeting itself. We also present the Call to Action that was consolidated from the closing statements of the nine EDUsummIT 2017 Thematic Working Groups.
\end{abstract}

Keywords Digital technology $\cdot$ Education systems $\cdot$ Informal learning $\cdot$ Creativity $\cdot$ Digital agency · Technology leadership · Professional development · Assessment · Upbringing · Educational policy $\cdot$ Sustainability $\cdot$ Scalability $\cdot$ EDUsummIT

\section{Introduction}

This special issue is the result of the Fifth International Summit on Information and Communication Technology in Education (EDUsummIT), which was held from September 18-20, 2017 in Borovats, Bulgaria. EDUsummIT is an invitational, working summit focusing on the integration of information and communication technology in education.

Joke Voogt

j.m.voogt@uva.nl

Gerald Knezek

gknezek@gmail.com

1 University of Amsterdam, Amsterdam, The Netherlands

2 Windesheim University of Applied Sciences, Zwolle, The Netherlands

3 University of North Texas, Denton, USA 
The EDUsummIT community consists of approximately 100 key stakeholders meeting biannually around the world. Previous EDUsummITs were held in The Hague (2009), Paris (2011) - together with UNESCO, Washington (DC) (2015) and Bangkok (2015-with UNESCO Bangkok. EDUsummIT2017 in Bulgaria was held under the patronage of UNESCO and the European Commission, specifically under the patronage of Mariya Gabriel, European Union Commissioner for the Digital Economy and Society, and Eva Maydel, member of the European Parliament Committee on the Internal Market and Consumer Protection (IMCO). Policy makers, practitioners and researchers from 31 countries discussed challenges and research-informed, practice-based strategies to effectively implement technology into teaching and learning. The next EDUsummIT will take place in Quebec, Canada, from September 29-October 2, 2019.

The EDUsummIT initiative started with the publication of the International Handbook on Information Technology in Primary and Secondary Education 10 years ago (Voogt and Knezek 2008). Based on an understanding that scholarly work does not easily find its way into policy and practice, the handbook editors initiated a dialog between policy makers, researchers and practitioners, which has become an open community, the EDUsummIT. Each EDUsummIT has a specific theme, determined in close collaboration with the local host. Before each summit participants collaborate online in thematic working groups (TWGs) to prepare for the discussions taking place at the summit face to face. EDUsummIT 2017 resulted in a Call to Action (see last section of this paper) and policy briefs delivered immediately after the completion of EDUsummIT 2017, at the QED'17 International UNESCO Workshop "Children in the Digital Era" held in the European Union building in Sofia, Bulgaria.

Outcomes from each of the first four EDUsummITs have been published in one of the major refereed journals in our field: EduSummIT 2009—Journal of Computer Assisted Learning (JCAL); EDUsummIT 2011-Journal of Computer Assisted Learning (JCAL); EDUsummIT 2013-Education and Information Technology (EAIT); and EDUsummIT 2015-Educational Technology and Society (ETS). We are honored to present the findings from EDUsummIT 2017 in a special issue of Technology, Knowledge and Learning (TKNL). We are also fortunate that collaborations developed through the EDUsummITs have extensively contributed to the Second Handbook on Information Technology in Primary and Secondary Education (Voogt et al. 2018) to be released in late 2018.

\section{Rethinking Learning in the Digital Age}

The theme of the EDUsummIT 2017 was Rethinking Learning in a Digital Age. This theme was inspired by the celebration of the international project Children in the Information Age, which started in 1985 in Bulgaria. Topics addressed in this project were, amongst others, school informatics, the family computer boom, new meanings of literacy, and computer use in schools. Project outcomes were discussed during an international conference in 1987 and captured in the book "Children in the information age: Opportunities for creativity, Innovation and new activities", edited by Sendov and Sanchez (1988). These topics are still relevant today.

The Thematic Working Groups (TWGs) at EDUsummIT 2017 discussed the summit theme from a specific perspective. The following key topics for the TWGs were determined: (1) education systems in the digital age: the need for alignment; (2) informal learning with technology; (3) professional development for technology-enhanced learning 
leaders; (4) digital agency to empower equity in the classroom; (5) formative assessment supported by technology; (6) developing creativity in teachers and learners; (7) learning from national policy experiences; (8) upbringing in a digital world: Opportunities and possibilities of schooling, and (9) sustainability and scalability of technology integration initiatives. Some of these topics evolved from previous EDUsummITs, while others such as Upbringing in the digital world were new and suggested by the local host. Within each TWG actual developments and issues were discussed from macro, meso and micro level perspectives.

\section{Contributions to the Special Issue}

In this special issue we present the scholarly work that resulted from discussions in the thematic working groups at EDUsummIT 2017. The first four contributions started from the perspective of the interactions with technology of (young) learners in the digital era.

In the first contribution Alona Forkosh Baruch and Ola Erstad (TWG 8) focus on the interrelation between upbringing and education. The authors identify the main areas of challenges for upbringing in the digital era as: (1) ecological (environmental) challenges, (2) intergenerational and intercultural challenges, (3) challenges in creating an educational continuum, and (4) challenge in upbringing digital citizens as informed adults. Baruch and Erstad also suggest recommendations to policymakers, researchers and practitioners for each of the challenge areas.

Learning does not only take place in schools, but also in families, at the work place and in leisure time. Cathy Lewin and her colleagues (TWG 2) discuss the challenges centered around defining informal learning - concluding that learning is multidimensional and has varying combinations of formal and informal attributes - and then highlight the potential of technology for integrating formal and informal learning attributes (Lewin and Charania 2018). The authors argue that for the learner, integration of formal and informal learning attributes should be an empowering process, enabling the learner to be self-directed, creative and innovative. This demands support from the teacher but also awareness and understanding from others such as parents, family, friends and community members. A conceptual model of such an ecosystem is presented to help further discussions within and between communities of researchers, policy makers and practitioners.

The development of creativity is widely considered to be a key component for today's learners. However, while the opportunities for developing creativity with the help of technology were discussed since the 1980s (e.g. Sendov and Sanchez 1988), creativity still is not considered a key component of schooling. Danah Henrikson and her colleagues (TWG 6) wondered during their discussions how the development of creativity with the help of technology in schools is fostered by educational policy. They reviewed the literature on this topic and examined how references to creativity in educational policy documents for K-12 education in six nations are (not) addressed. The results indicate the need for alignment between intentions and actions to realize the enactment of creativity and technology as a key component of 21 st century education. They call for a coordinated effort of policy makers, practitioners and researchers as a means to realize this enactment.

The contribution of Don Passey and colleagues (TWG 4) elevates the discourse about equity in the digital age (Resta et al. 2018). The authors focus on the concept digital agency, which is defined in terms of three component parts-digital competence, digital confidence, and digital accountability. They contend that from an equity perspective all 
learners need to be able to develop agency in all three parts to live, work and learn in current society. The authors conclude "Fundamentally, unless people have agency, they cannot act in their own interests, and are effectively powerless. Thus, equipping citizens with the skills and attributes required to exercise digital agency is a big societal challenge involving all stakeholders, including policy makers, technology leaders, practitioners and the research community" (Passey et al. 2018).

The second set of contributions focuses on conditions at the meso and macro level that need to be in place to realize effective, sustainable and effective learning and teaching with technology in education.

Technological developments are increasingly seen as an important means for assessment of, as and for learning (Webb and Ifenthaler 2018). During EDUsummIT 2017 Mary Webb and colleagues (TWG 5) focused on IT-enabled formative assessment of 21 st century skills. In their publication the authors first identify key aspects of assessment processes that can be facilitated by digital technologies: (a) datafication of learning; (b) feedback and scaffolding; (c) peer assessment, and (d) peer feedback. The authors then explore how these processes can be applied in formative assessment of 21 st century skills (e.g. creativity, complex problem solving, communication, collaboration and self-regulated learning)— taking into account that 21 st century skills also incorporate complex motivational and affective components. The authors argue that for the near future the complexity of assessing 21st century skills implies IT-enabled techniques will need to be combined with more traditional methods of teacher and peer assessment.

Outcomes from research (e.g. Dexter 2018; Riel and Becker 2008) and experiences from practice show the need for leaders at the school level, who support and scaffold teaching and learning with technology. These 'learning leaders' have important roles in facilitating and supporting the effective and innovative integration of technology in schools. In the contribution of Christensen and colleagues (TWG 3), two types of learning leaders are distinguished, viz. school administrators (principals, heads of department etc.) and teacher leaders. The argument is made that identifying the characteristics of school administrators and teacher leaders that are strong in integrating technology in their schools is a first step in moving schools toward more effective technology integration. The contribution addresses the role learning leaders have in the effective use of technology and its assessment in the learning environment, as well as the types of professional development that could best support learning for these leaders.

The contribution of Butler and colleagues (TWG 1) centers on the need for alignment in education systems to realize technology integration. The paper addresses two questions of: (a) if and how all the parts of an education system work together to support the type of learning envisioned in the 21 st century, and (b) if there is alignment, what is the purpose/ vision of that education system and does it meet the needs of its learners. Two frameworks, grounded in the literature, are discussed to foster the alignment between policy and practice. The first framework is proposed as a tool to create alignment between policy and practice, as illustrated with an example of IT policy development for education in Ireland. The second framework is proposed to allow policy makers and stakeholders to develop a shared vision on the purpose of IT policy development for education — and could be used as a start of the policy making process at the system and school level.

With the increasing relevance of technology in education and society, policy makers face challenges in properly preparing students for successful participation in the knowledge society (Eickelmann 2018). Gibson and colleagues (TWG 7) focus in their paper on the need to create future ready information technology national policies for education. The paper identifies four challenges concerning the design, implementation, and evaluation of 
such policy: (1) creating future ready policy, (2) achieving systemic perspectives in stakeholders, (3) promoting commitment to learning from policy, and (4) developing and implementing supportive processes. The authors discuss strategy perspectives and solutions, as well as tactics that could be applied to advance a nation's educational system, empowered by technology.

In the final contribution Niederhauser and colleagues (TWG 9) point out that the education sector of the world has been engaged in 30 years of educational technology initiatives with large expenditures, but with limited returns on these substantial financial investments, with regard to positive impact on learning (e.g. Kirkwood and Price 2013). The minimal influence of educational technology initiatives on pedagogical practices has made it clear that simply providing access to technology is not sufficient to address the kinds of pedagogical change hoped for by reformers (Niederhauser and Lindstrom 2018). The authors contend that if the ultimate goal is to integrate classroom technology use that is more meaningful, purposeful and relevant to students, then establishing productive partnerships among stakeholders, identifying research-informed approaches to technology integration that are sustainable and scalable, and developing sustainable and scalable approaches to technology integration that are based on research literature rather than policy initiatives, can help inform this process.

\section{Overaching Themes: A Call to Action}

Closing presentations of the initial outcomes from each of the thematic working groups (TWGs) participating in EDUsummIT 2017 revealed several common themes that were combined to produce a call to action first published in Lai et al. (2018). These jointly recommended actions include 19 challenges for researchers, leaders and policy makers, categorized within the areas of (a) students and learning with ICT, (b) professional development for integrating technology, and (c) educational system policies for infusing technologies. The Call to Action is presented below.

\subsection{Students and Learning with ICT}

- To recognize that digital agency, as an individual's ability to control and adapt to a digital world, is a critical goal for social, civic and economic well-being.

- To recognize that citizens including young people are able to engage as producers rather than consumers in order to shape the interaction between technology and society.

- To create awareness of family, community and peer challenges for promoting digital citizenship and new opportunities and risks of upbringing in a digital world.

- To rethink inter-generational and intercultural dynamics of family and educational institutes linked to upbringing, in a continuous manner.

- To recognize creativity as an important component of student development.

- To embed creativity throughout the curriculum in both what we teach and assess, and in teacher professional standards.

- To develop a rich array of cases/examples that help exemplify and visualize what creativity looks like across teaching and learning contexts.

- To promote informal learning in education through empowering students, policy makers should facilitate connections between informal and formal learning and enable teachers to recognize and integrate informal learning in their pedagogy. 


\subsection{Professional Development for Integrating Technology}

- To encourage professional development that includes the recognition that leaders facilitating technology-enhanced learning are important change agents in the implementation of policies.

- To encourage policy makers to create opportunities for developing teacher capacity to identify, foster development of, and formatively assess 21 st century skills (e.g. creativity, problem solving, self regulation, critical thinking, collaboration, communication, digital literacy).

- To establish global and local networks of professional development of leaders who facilitate technology-enhanced learning.

\subsection{Educational System Policies for Infusing Technologies}

- To develop an actionable vision that has buy-in from all stakeholders to ensure alignment within the system.

- To use frameworks such as the UNESCO Framework (2011) as tool to guide alignment and implementation within the system.

- To develop productive partnerships among all stakeholders to advance capacity building for ICT use in schools through the co-design of research with real commitment and ownership from all stakeholders-at appropriate levels.

- To communicate and connect with policymakers and educators to ground policies in evidence informed knowledge to protect policy and practice from the latest fads of educational technology.

- To be aware of the affordances and challenges when stakeholders use data to make decisions for formative assessment.

- To create opportunities for collaborative work with stakeholders in order to examine the complex connections between data collection, data interpretation and meaningful data use to support teachers and learners.

- To use real time data systems to monitor and evaluate educational processes and outcomes through a balance of valued indicators in dynamic systems models.

And

- To develop future ready policy visions aligned with global development goals.

These recommendations were developed from an understanding that the learning landscape is undergoing fundamental changes, requiring new methods and perspectives to capture the capabilities of digital technologies to augment education. Organizations and individuals interested in rethinking learning in the digital age are encouraged to freely reference these recommendations. The nine journal articles contained in this special edition provide substantial support for this Call to Action.

Open Access This article is distributed under the terms of the Creative Commons Attribution 4.0 International License (http://creativecommons.org/licenses/by/4.0/), which permits unrestricted use, distribution, and reproduction in any medium, provided you give appropriate credit to the original author(s) and the source, provide a link to the Creative Commons license, and indicate if changes were made. 


\section{References}

Dexter, S. (2018). The role of leadership for information technology in education: Systems of practice. In J. Voogt, G. Knezek, C. Christensen, \& K.-W. Lai (Eds.), Second international handbook of information technology in primary and secondary education. Cham: Springer.

Eickelmann, B. (2018). Cross-national policies on information and communication technology in primary and secondary education schools. In J. Voogt, G. Knezek, C. Christensen, \& K.-W. Lai (Eds.), Second international handbook of information technology in primary and secondary education. Cham: Springer.

Kirkwood, A., \& Price, L. (2013). Examining some assumptions and limitations of research on the effects of emerging technologies for teaching and learning in higher education. British Journal of Educational Technology, 44(4), 536-543.

Lai, K-W, Voogt, J. \& Knezek, G. (2018). Rethinking learning in the digital age. EDUsummIT summary reports. Borowitz: EDUsummIT conference. Retrieved from http://unesco.unibit.bg/en/EDUsummIT1 7

Lewin, C., \& Charania, A. (2018). Bridging formal and informal learning through technology in the twentyfirst century: Issues and challenges. In J. Voogt, G. Knezek, C. Christensen, \& K.-W. Lai (Eds.), Second international handbook of information technology in primary and secondary education. Cham: Springer.

Niederhauser, D. S., \& Lindstrom, D. L. (2018). Instruction technology integration models and frameworks: Diffusion, competencies, attitudes and dispositions. In J. Voogt, G. Knezek, C. Christensen, \& K.-W. Lai (Eds.), Second international handbook of information technology in primary and secondary education. Cham: Springer.

Passey, D., Shonfeld, M., Appleby, L., Judge, M., Saito, T., Smits, A. (2018). Digital agency- empowering equity in and through education. Technology, Knowledge and Learning. https://doi.org/10.1007/s1075 8-018-9384-x.

Resta, P., Laferrière, T., McLaughlin, R., \& Kourago, A. (2018). Issues and challenges related to digital equity: An overview. In J. Voogt, G. Knezek, C. Christensen, \& K.-W. Lai (Eds.), Second international handbook of information technology in primary and secondary education. Cham: Springer.

Riel, M., \& Becker, H. (2008). Characteristics of teacher leaders for information and communication technology. In J. Voogt \& G. Knezek (Eds.), International handbook of information technology in primary and secondary education (pp. 397-417). New York: Springer.

Sendov, B., \& Sanchez, I. (1988). Children in the information age opportunities for creativity, innovation and new activities. New York: Elsevier. https://doi.org/10.1016/C2013-0-03850-9.

Voogt, J., \& Knezek, G. (Eds.). (2008). International handbook of information technology in primary and secondary education. New York: Springer.

Voogt, J., Knezek, G., Christensen, C., \& Lai, K.-W. (Eds.). (2018). Second international handbook of information technology in primary and secondary education. Cham: Springer.

Webb, M., \& Ifenthaler, D. (2018). Assessment as, for and of twenty-first century learning using information technology. In J. Voogt, G. Knezek, C. Christensen, \& K.-W. Lai (Eds.), Second international handbook of information technology in primary and secondary education. Cham: Springer. 